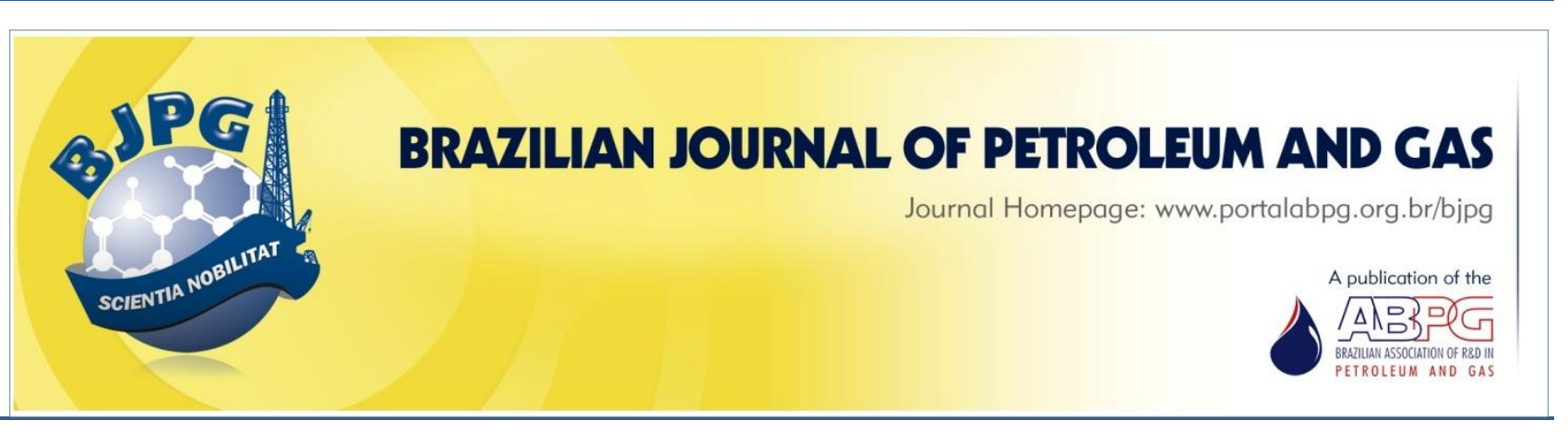

\title{
MODELING AND SIMULATION OF A HORIZONTAL THREE-PHASE SEPARATOR: INFLUENCE OF PHYSICOCHEMICAL PROPERTIES OF OIL
}

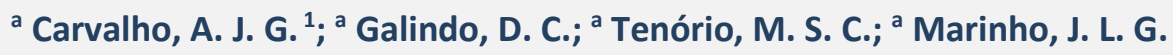 \\ ${ }^{a}$ Federal University of Alagoas, Technology Center, Maceió - AL, Brazil
}

Received: 04.08.2020 / Revised: 27.11.2020 / Accepted: 05.12.2020 / Published on-line: 07.01.2021

\begin{abstract}
Fluids produced from oil reservoirs typically contain oil, natural gas, water, sediments, in varying amounts, and contaminating gases. Considering that economic interest usually targets mostly oil and gas, primary processing is used to separate water/oil/gas, in addition to treating these phases. Therefore, the well stream should be processed as soon as possible after reaching the surface. Separator vessels are among the main equipment used at surface production facilities, being responsible for the separation of the produced phases. This work focuses on studying the fluid dynamic behavior in a horizontal three-phase separator. To accomplish this goal, we used the computer fluid dynamics software ANSYS CFX. First, we performed a detailed analysis of a "Standard Case" to understand in detail the entire separation process within the vessel. The results show the three phases through the simulation time, analyses of the separation efficiency, different fluids flow lines, pressure gradient inside the vessel, and effect of the diverter baffle. It also considers a variation of fluid flow at the inlet of the separator. These analyses include pictures of all cases studied. Afterwards, some parameters of the standard case were altered to evaluate its influence on fluid dynamics behavior and the functioning of the separator vessel. At last, we analyzed the influences of oil density and viscosity on the separation. The oil quality affects the primary separation directly, as the oil density and viscosity increase, for example, increases the drag between the fluids and decreases the rate of sedimentation, which stickles the separation process difficult. Two out of the three cases generated satisfactory results. The simulation with the heaviest oil presented the worse results.
\end{abstract}

\section{KEYWORDS}

separator vessel; computer fluid dynamics; ANSYS CFD

\footnotetext{
${ }^{1}$ To whom all correspondence should be addressed.

Address: Federal University of Alagoas, Technology Center, Av. Lourival Melo Mota - Cidade Universitária, Maceió - AL, Brazil Zip Code: 57072-900 | Phone number: +55 2182 3214-1292 | e-mail: augustojgc@gmail.com doi:10.5419/bjpg2020-0016
} 


\section{INTRODUCTION}

The use of fossil fuels as an energy source has driven many changes in the oil industry over the years, significantly boosting technological advances in the area. As an example, oil and its products correspond to about $32 \%$ of the world's energy matrix (EPE, 2018). This mineraloid is formed by the decomposition of organic matter which, under the action of pressure and heat, generates mixtures of compounds consisting mainly of hydrocarbons with structures that range from simpler to more complex chains. In an oil reservoir, there is also interstitial water, coming from the rock formation processes, and natural gas (Silva et al., 2007).

The reservoir configuration will depend on local pressure and temperature, the differences in density and immiscibility between the phases, and it is common to find natural gas occupying the upper part of the interior of the reservoir, while oil and salty water occupy the lower part. When the production of reservoir fluids occurs, in addition to oil and natural gas production, sediment, the socalled "production facilities", interstitial water and corrosive gases like $\mathrm{CO}_{2}$ and $\mathrm{H}_{2} \mathrm{~S}$ are produced (Silva et al., 2007). The produced fluids need to go through separation and refining processes to have a market value of the product: oil and gas.

The first stage of separation is carried out in the primary petroleum processing plant and consists of using equipment such as the separating vessel, being responsible for separating the phases of the fluid produced. It can be classified in terms of position, as horizontal or vertical, or in terms of the number of phases, as two-phase or three-phase (Andrade, 2014; Diniz, 2017).

The use of computational fluid dynamics software can be helpful in the study of fluid behavior within a separating vessel. Among these computational programs, ANSYS CFX is capable of simulating the separation of phases in a separating vessel. This allows the visualization of phenomena that occur during the separation process, obtaining pressure, velocity, and residence time profiles, and pointing out best configuration choices for a given project.

The study of various aspects of primary petroleum processing, including the separating vessels, has been conducted by several authors such as Silva (2004), Andrade (2014), and Anjos (2015). When it comes to numerical modeling, the literature is more restricted. However, recent studies made by Ghaffarkhah et al. (2017), Triwibowo et al. (2017), Scapin et al. (2017), and Ahmed et al. (2019) show the relevance of computer modeling and its potential uses in industry. All studies mentioned above address Horizontal Three-Phase Separator (HTPS), using Computational Fluid Dynamics (CFD) software.

Ghaffarkhah et al. (2017) studied two semiempiric models, one by Arnold and Stewart and another by Monnery and Svrcek, for dimensioning HTPS, developing a comparative study between them. For the analysis of fluid behavior, the authors used a combination of Volume of Fluid (VOF) and Discrete Particle Method (DPM) models. The work of Triwibowo et al. (2017) focused on the modeling and simulation of a steady-state HTPS. To develop this study, Triwibowo et al. (2017) used the multiphase flow model VOF. Scapin et al. (2017) presented the analysis of a three-phase separator, based on a multifluid eulerian- eulerian model of Navier-Stokes equations. The aim of these authors was to construct a consistent numerical scheme for multiphase flow involving more than two phases.

Ahmed et al. (2019) compared two commonly used multiphase flow models, Eulerian and VOF, to predict separation performance and fluid flow patterns in an HTPS. To obtain experimental data, the authors developed two distinct three-phase separator vessels on a pilot scale: one operating at a low flow rate and the other at a high gas volume flow rate. By comparing the results of experimental and numerical data, the authors concluded that numerical simulation is highly recommended to size an industrial scale separator using the appropriate CFD model. Ghaffarkhah et al. (2017), Triwibowo et al. (2017), Scapin et al. (2017), and Ahmed et al. (2019) used their respective multiphase flow models associated with the turbulence model $k-\varepsilon$.

Thus, this work studies fluid dynamic behavior of a three-phase water-oil-gas mixture in a horizontal separating vessel, varying influence of oil properties. Such analysis was performed through simulations in the ANSYS CFX computational fluid dynamics software. 


\section{METHODOLOGY}

The present work used only one geometry for the three-phase horizontal separating vessel. The dimensions used were based on the work Anjos (2015), with an increase in the total length of the vessel, which is recommended for three-phase separators, because they have sections of the accumulation both for oil and water. Figure 1 shows the lateral view of the separating vessel used, as well as its dimensions. This separating vessel has two internal structures: a diverter baffle near the inlet of fluids and a plate that separates the accumulation sections from the water and gas, as shown in Figure 2a. The dimensions of the separating vessel are shown in Figure $2 b$.

\subsection{Mesh generation}

The mesh pattern for this work is unstructured. It is formed by 315936 elements and 56129 nodes (Figure 3a). This mesh is not completely regular. In the smaller parts, such as the plates, entrance and exits (Figure $3 b$ ), have a higher density of elements, providing more precise the results.

\subsection{Mathematical modeling}

The simulations for each case took an average of one hour to be processed. This work was performed using the ANSYS Student 18.2 package, which includes the ANSYS CFX 18.2 software, the computational fluid dynamics software used to perform simulations and analyze results. The

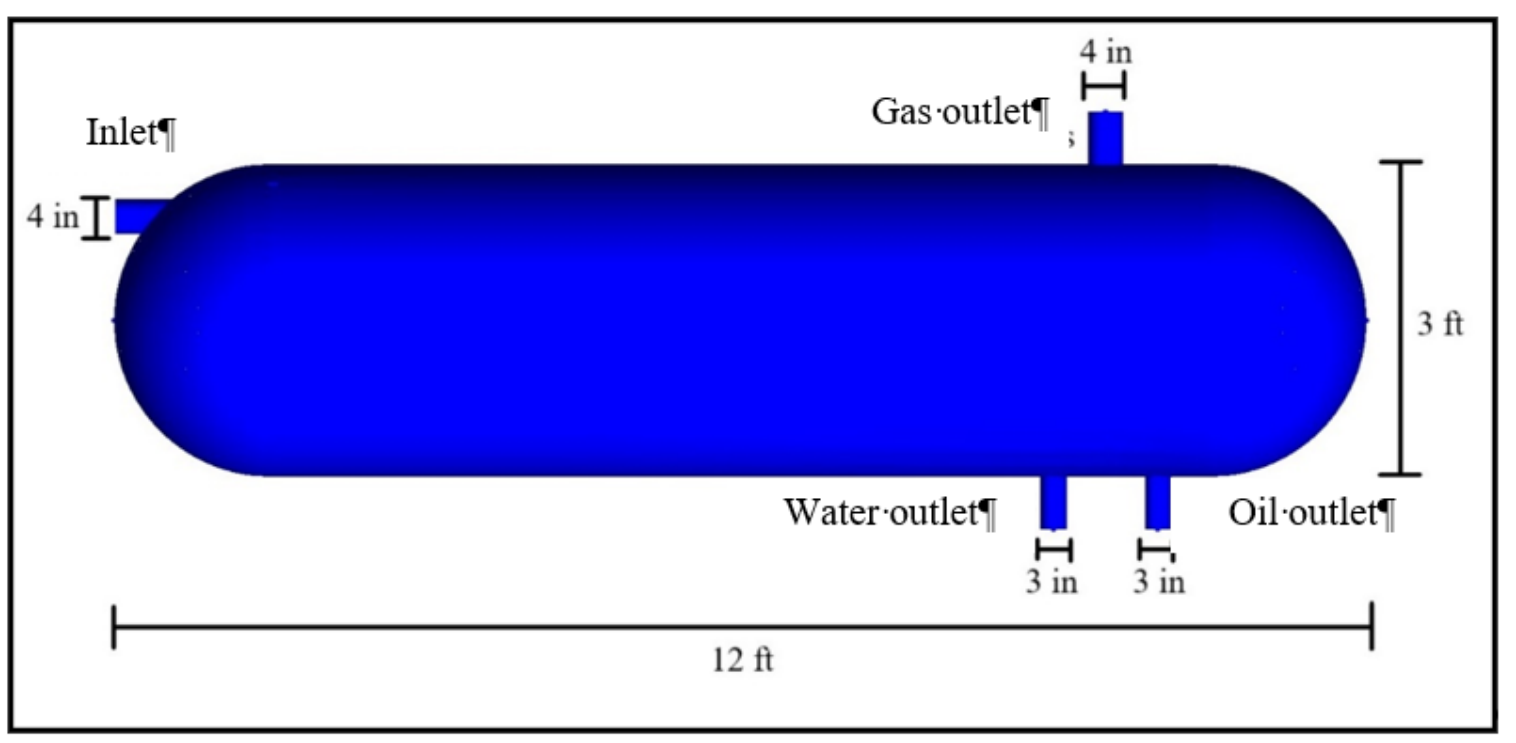

Figure 1. Three-phase horizontal separating vessel (side view).

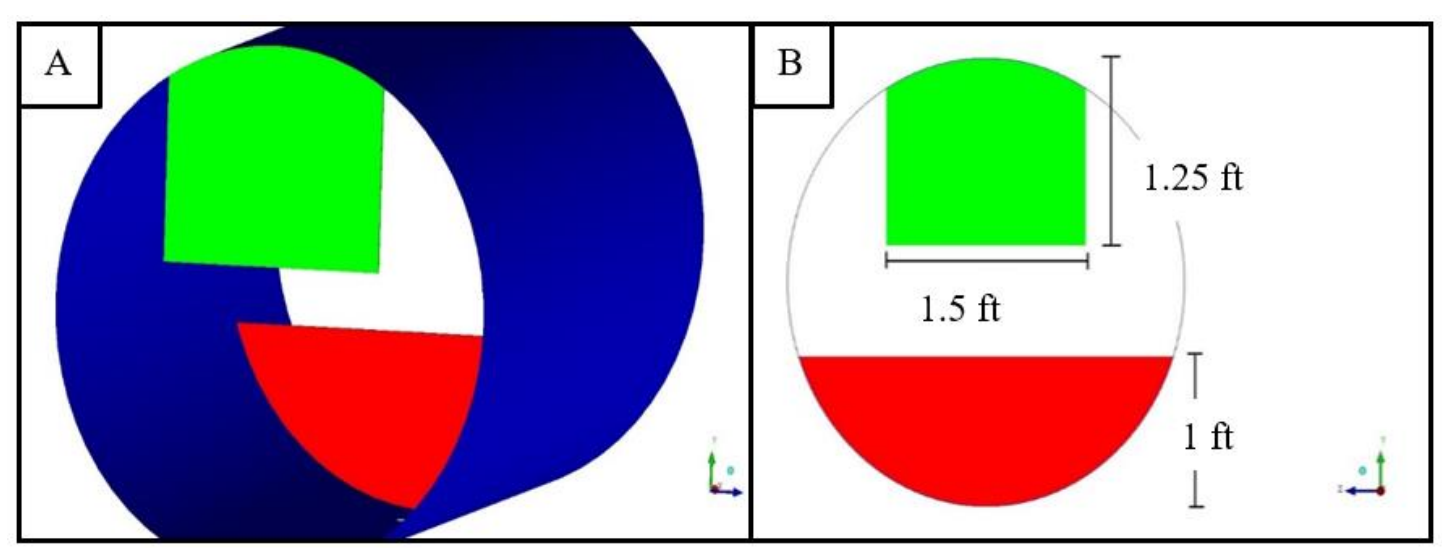

Figure 2. a) Internal structures of the separator and b) dimensions. 


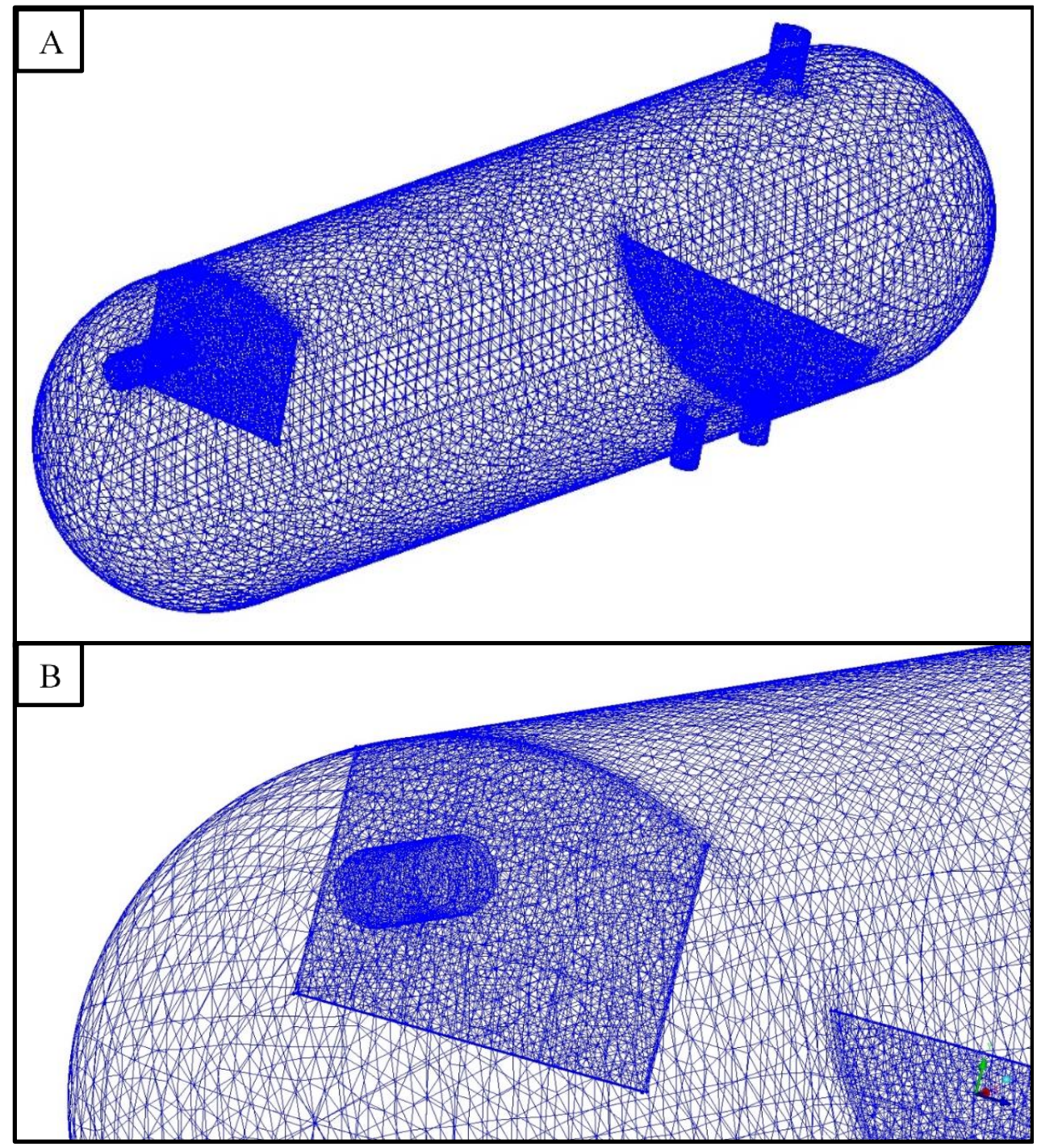

Figure 3. a) Unstructured numerical mesh developed; b) Detailed view of the deflector plate and gas outlet.

simulations were performed in a computer with Intel Core i5 quad-core $3.5 \mathrm{GHz}$ processor and 16 GB of DDR3 1600 RAM.

For the construction of the numerical mesh, ICEM CFD 13.0 was used. This software, which is part of the ANSYS package, is a powerful tool capable of working with both structured and unstructured meshes, from the simplest to the most complex ones. The mathematical modeling of the problem used a Eulerian-Eulerian model. It consists of adopting a time interval, choosing a section or a volume of control in space and considering all the particles that pass through this location (Triwibowo et al., 2017).

To simplify the problem, some hypotheses were considered: 1) Slight temperature variation in the region analyzed (isothermal process); 2) Transient regime; 3) Effect of gravity; 4) Three-dimensional domain in Cartesian coordinates; 5) Constant physicochemical properties and no chemical reactions. Through these simplifications it is possible to reduce the number of required equations to three. These equations are applied to each of the control volumes with the use of ANSYS CFX, obtaining a numerical resolution.

\subsection{Fluid domain equations}

In fluid mechanics, the continuity equation, described by Equation 1, determines that the flow with which mass enters a system is equal to the flow with which mass leaves the system plus the accumulated mass. Its form differs is given by:

$\nabla .\left(r_{\alpha} \rho_{\alpha} \vec{U}_{\alpha}\right)=-\frac{\partial \rho}{\partial t}$ 


\section{Where:}

$r_{\alpha}$ is volumetric fraction of phase $\alpha$ (nondimensional);

$\rho_{\alpha}$ is specific mass of phase $\alpha$ in $\mathrm{kg} / \mathrm{m}^{3}$;

$\vec{U}_{\alpha}$ is speed of phase $\alpha$ in $\mathrm{m} / \mathrm{s}$;

$t$ is time in seconds.

The conservation of momentum is described by Equation 2, which encompasses the forces acting on the flow.

$$
\begin{aligned}
& \nabla \cdot\left[r_{\alpha}\left(\rho_{\alpha} \vec{U}_{\alpha} \otimes \vec{U}_{\alpha}\right)\right]+\frac{\partial(\rho V)}{\partial t}= \\
& =r_{\alpha} \nabla p+\nabla\left[r_{\alpha}\left(\tau_{\alpha}+\tau_{\alpha}^{\text {turb }}\right)\right]+\vec{M}_{\alpha}
\end{aligned}
$$

Where:

$\mathrm{p}$ is pressure in $\mathrm{Pa}$;

$\Delta p$ is pressure gradient;

$\tau_{\alpha}$ is tension in phase $\alpha$ in $\mathrm{kg} / \mathrm{ms}^{2}$;

$\tau_{\alpha}^{t u r b}$ is turbulent tension of Reynolds in phase $\alpha$ in $\mathrm{kg} / \mathrm{ms}^{2}$;

$\vec{M}_{\alpha}$ describes the interfacial forces acting in phase $\alpha$ due to the presence of other phases in $\mathrm{N} / \mathrm{m}^{3}$;

The value of $\vec{M}_{\alpha}$ can be calculated from Equation (3):

$\vec{M}_{\alpha}=C_{D} \rho_{\alpha \beta} A_{\alpha \beta}\left|\vec{U}_{\beta}-\vec{U}_{\alpha}\right|\left(\vec{U}_{\beta}-\vec{U}_{\alpha}\right)$

Where:

$\rho_{\alpha \beta}$ is specific mass of mixture in $\mathrm{kg} / \mathrm{m}^{3}$;

$A_{\alpha \beta}$ is specific mass of interfacial area in $\mathrm{m}-1$;

$\vec{U}_{\alpha}$ is speed of phase $\alpha$ in $\mathrm{m} / \mathrm{s}$;

$\vec{U}_{\beta}$ is speed of phase $\beta$ in $\mathrm{m} / \mathrm{s}$.

The value of $A_{\alpha \beta}$ is defined as a function of the dispersed fraction and the diameter of the particles according to Equation (4):

$A_{\alpha \beta}=\frac{6 r_{\beta}}{d_{\beta}}$

\section{Where:}

$r_{\beta}$ is the fraction of dispersed phase (nondimensional);

$d_{\beta}$ is the diameter of phase particles $\beta$ (nondimensional).

\subsection{Turbulence model}

The k- $\varepsilon$ turbulence model was used for this work. It involves the modeling of two differential transport equations, one for turbulent kinetic energy $k$ and the other for $\varepsilon$, which represents the rate of dissipation of turbulent kinetic energy per unit of mass. It is a very popular turbulence model, providing a good relationship between computational effort and accuracy. It is represented by equations (5) and (6).

$\nabla(\rho \vec{U} k)=\nabla\left[\left(\mu+\frac{\mu_{t}}{\sigma_{k}}\right) \nabla k\right]+\left(P_{k}-\rho \varepsilon\right)$
$\nabla(\rho \vec{U} k)=\nabla\left[\left(\mu+\frac{\mu_{t}}{\sigma_{\varepsilon}}\right) \nabla \varepsilon\right]+\frac{\varepsilon}{k}\left(C_{\varepsilon 1} P_{k}-C_{\varepsilon 2} \rho \varepsilon\right)$

Where:

$\varepsilon$ is rate of turbulent dissipation in $\mathrm{m}^{2} / \mathrm{s}^{3}$;

$k$ is turbulent kinetic energy in $\mathrm{kg} \cdot \mathrm{m}^{2} / \mathrm{s}^{2}$;

$\mu$ is the dynamic viscosity in N.s/m²;

$\mu_{t}$ is turbulent viscosity in N.s/m²;

$\sigma_{k}, \sigma_{\varepsilon}$, and $C_{\varepsilon}$ are dimensional constants of turbulence model k- $\varepsilon$

\subsection{Boundary conditions and fluids properties}

In this paper, the efficiency of fluid separation is evaluated in several situations through the modification of some variables. The standard operating conditions were $25{ }^{\circ} \mathrm{C}$ of temperature and 17.2 bar of pressure. The fluid properties for such conditions are shown in Table 1.

In order to make the operating conditions of the separating vessel in the standard case consistent with reality, both maximum gas and liquid capacity have been calculated. The gas and liquid capacities are represented, respectively, by Equations 7 and 8. Equation 7, proposed by Souders-Brown, is empirical and does not consider the length of the vessel and the level of liquid inside of it. 
Table 1. Properties of fluids in standard conditions.

\begin{tabular}{cccc}
\hline & Oil & Gas & Water \\
\hline Specific Mass & $813,464 \mathrm{~kg} / \mathrm{m}^{3}$ & $0.7236 \mathrm{~kg} / \mathrm{m}^{3}$ & $997 \mathrm{~kg} / \mathrm{m}^{3}$ \\
Dynamic Viscosity & $0.021 \mathrm{~kg} / \mathrm{ms}$ & $1.08 \mathrm{E}-05 \mathrm{~kg} / \mathrm{ms}$ & $8.899 \mathrm{E}-04 \mathrm{~kg} / \mathrm{ms}$ \\
Surface Tension & $0.072 \mathrm{~N} / \mathrm{m}$ & - & $0.072 \mathrm{~N} / \mathrm{m}$ \\
Constant Pressure Heat Capacity & $2140 \mathrm{~J} / \mathrm{kg} . \mathrm{K}$ & - & $4181 \mathrm{~J} / \mathrm{kg} . \mathrm{K}$ \\
Average Droplet Diameter & $100 \mu \mathrm{m}$ & - & $100 \mu \mathrm{m}$ \\
\hline
\end{tabular}

Sources: Silva \& Marinho (2016), Kharoua (2012), ANSYS (2013), and Copergás.

Table 2. Physicochemical properties of oil.

\begin{tabular}{cccc}
\hline Simulation & Specific mass $\left(\mathbf{k g} / \mathbf{m}^{\mathbf{3}}\right)$ & ${ }^{\circ} \mathbf{A P I}$ & Viscosity (Pa.s) \\
\hline 1 & 813.464 & 42.28 & 0.021 \\
2 & 845 & 35.80 & 0.03 \\
3 & 870 & 30.99 & 0.05 \\
\hline
\end{tabular}

$q_{s t}=\frac{2,4 D^{2} K p_{o p}}{z(T+460)} \sqrt{\frac{\rho_{L}-\rho_{g}}{\rho_{g}}}$

Where:

$q_{s t}$ is gas capacity at standard conditions in MMscfd;

$D$ is the inner diameter of the vessel in $\mathrm{ft}$;

$p_{o p}$ is the operating pressure in psia;

$T$ is the operating temperature in ${ }^{\circ} \mathrm{F}$;

$Z$ is gas compressibility factor (non-dimensional);

$\rho_{L}$ is specific mass of the liquid under operating conditions in $\mathrm{lbm} / \mathrm{ft}^{3}$;

$\rho_{g}$ is specific mass of the gas under operating conditions in $\mathrm{lbm} / \mathrm{ft}^{3}$;

$K$ is an empirical factor (non-dimensional).

$q_{L}=\frac{1440 V_{L}}{t}$

Where:

$q_{L}$ is liquid capacity in bbl/d;

$V_{L}$ is sedimentation volume of liquid in bbl;

$t_{r}$ is retention time in minutes.

In the boundary conditions, a mixture with $92 \%$ gas and $8 \%$ liquids, divided into oil (6\%) and water
(2\%) was considered for the inlet (Nakayama, 1999). In the vessel walls $(0.0456 \mathrm{~mm}$ of medium roughness) and deflector and separator plates, the slip wall condition was admitted, in which the relative velocity of the fluid in relation to the wall is null.

The gas outlet is of opening type, with standard relative pressure. For the liquid outlet, a constant and negative velocity of $0.25 \mathrm{~m} / \mathrm{s}$ was applied. The initial condition of the vessel considered it being full, with an oil-water mixture composed $50 \%$ of each phase up to $2 / 3$ of the height, and the rest being filled with gas.

All simulations were performed in a transient regime with a maximum number of 20 loops for each iteration. Each case was simulated for a total time of 20 minutes with time steps of 10 seconds having a convergence criterion of $10-4 \mathrm{~kg} \cdot \mathrm{s}^{-1}$.

\section{CASE STUDY ANALYSIS}

\subsection{Standard case}

The standard case, used as a basis for further studies, considered an input velocity of $13 \mathrm{~m} / \mathrm{s}$ (flow rate of $0.105395 \mathrm{~m}^{3} / \mathrm{s}$ ) with fractions of $92 \%$ gas, $6 \%$ oil, and $2 \%$ water. Physicochemical properties are demonstrated in Table 2. This results in a flow rate of 3436.71 bbl/day oil, $1145.57 \mathrm{bbl} /$ day water, and 0.3 MMscfd gas. 


\subsection{Physicochemical properties of oil variation}

This case analyzed the influence of the variation in the physicochemical properties of the oil. For the properties not present in Table 2 below, the properties shown in Table 1 were considered. In all cases, gas and water properties remained constant.

Besides the standard case and the analysis of the fluid flow variation, other studies can be done. Among them, the variations of the gas/liquid ratio, oil/water ratio, and the variation of fluid flow at the separator inlet.

\section{RESULTS AND DISCUSSION}

First, a detailed analysis of the standard case was performed. Afterwards, the results of the other cases were discussed, analyzing the influence of fluid flow variations.

\subsection{Standard case}

The Figures 4, 5, and 6 show, respectively, the volumetric fractions of oil, water, and natural gas inside the separator over 20 minutes.

After the analysis of Figures 4,5 , and 6 , it is possible to see that the separator worked out as expected. At the end of the simulation, the separation of the three phases inside the equipment was obtained, as well as the flow of the required fluids in the three outlets of the separator vessel. This behavior is very similar to those obtained by Ghaffarkhah et al. (2017) and Triwibowo et al. (2017).

Through the results obtained, visually and numerically, some preliminary observations can be made:

i. In the first minute it is possible to observe a considerable drop in the level of liquid inside the vessel. During this time there is still no stabilization of the flow in the water and oil outlets. Subsequently, the velocities at the

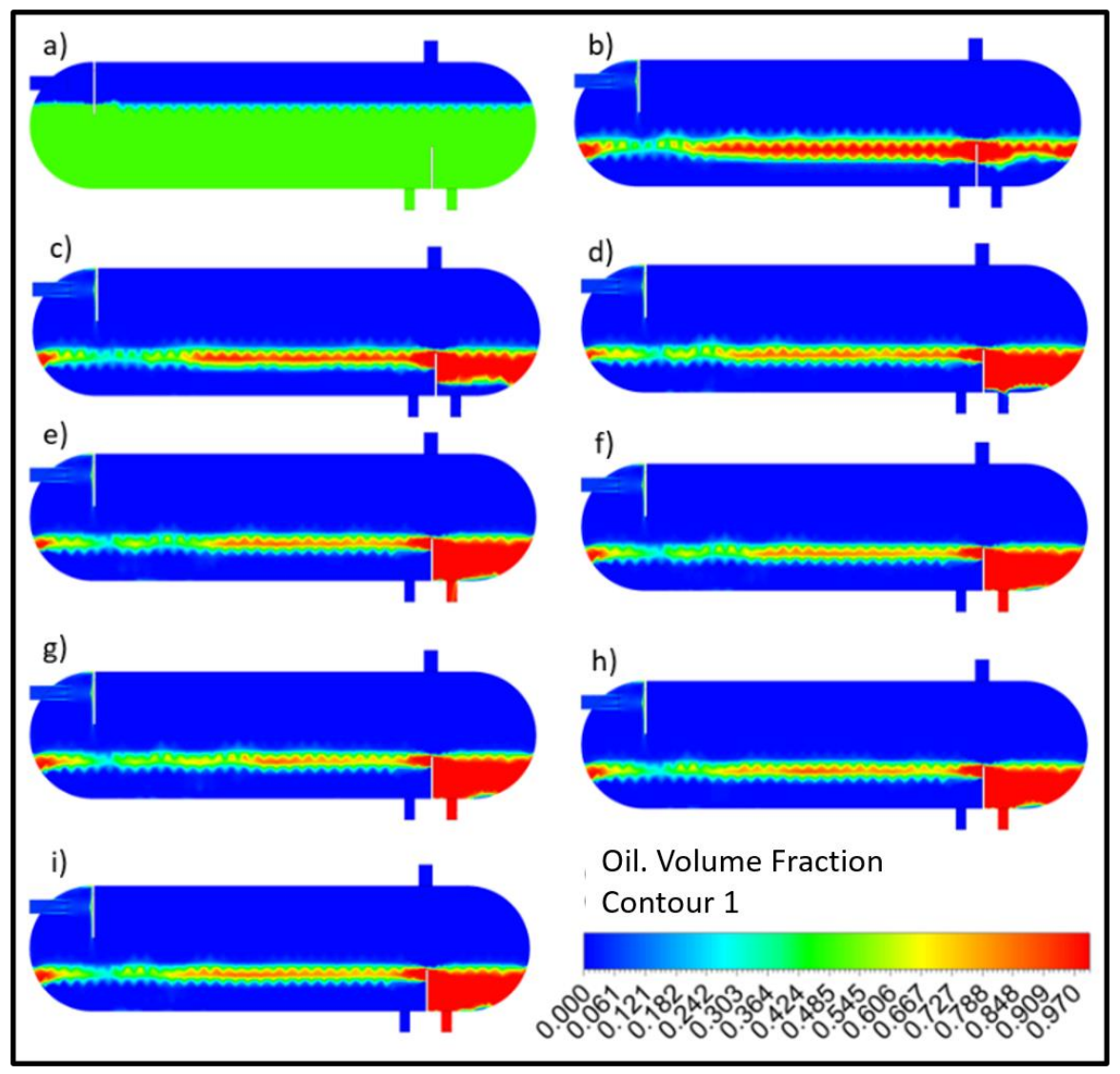

Figure 4. Oil volumetric fraction in a) $0 \mathrm{~s}$, b) $150 \mathrm{~s}$, c) $300 \mathrm{~s}$, d) $450 \mathrm{~s}$, e) $600 \mathrm{~s}$, f) $750 \mathrm{~s}, \mathrm{~g}) 900 \mathrm{~s}$, h) $1050 \mathrm{~s}$ and i) $1200 \mathrm{~s}$. 


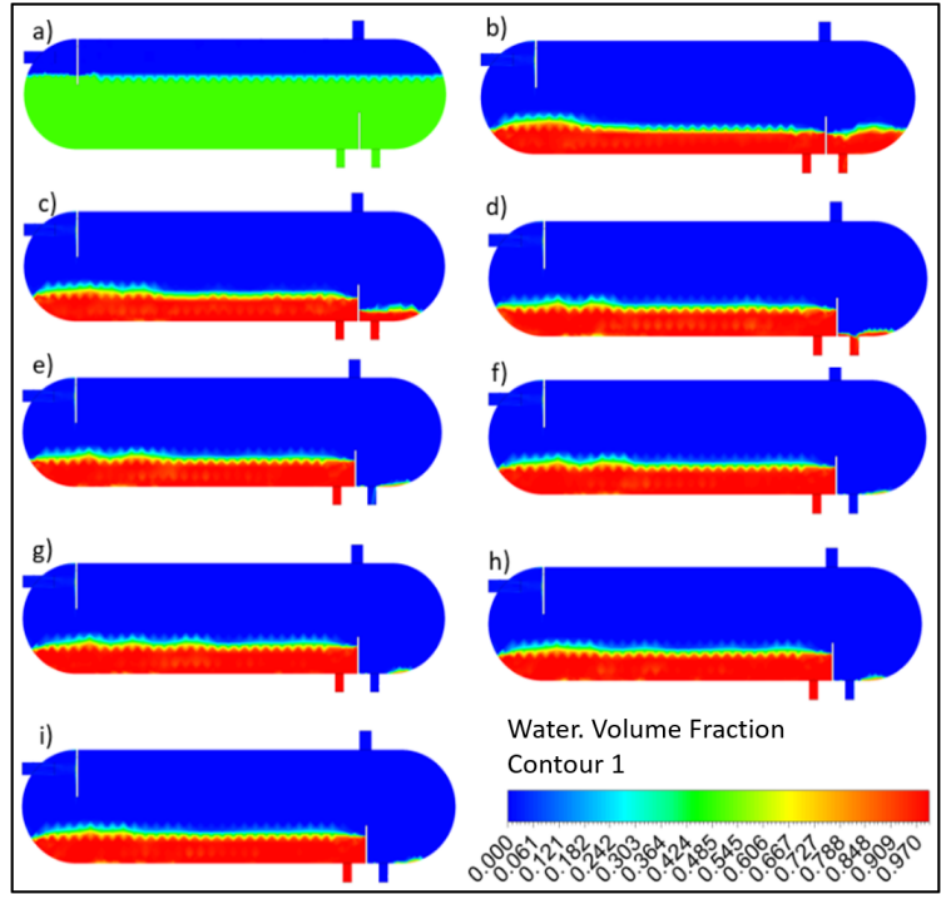

Figure 5. Water volumetric fraction a) $0 \mathrm{~s}$, b) $150 \mathrm{~s}, \mathrm{c}) 300 \mathrm{~s}$, d) $450 \mathrm{~s}$, e) $600 \mathrm{~s}$, f) $750 \mathrm{~s}, \mathrm{~g}) 900 \mathrm{~s}, \mathrm{~h}) 1050 \mathrm{~s}$ and i) $1200 \mathrm{~s}$.

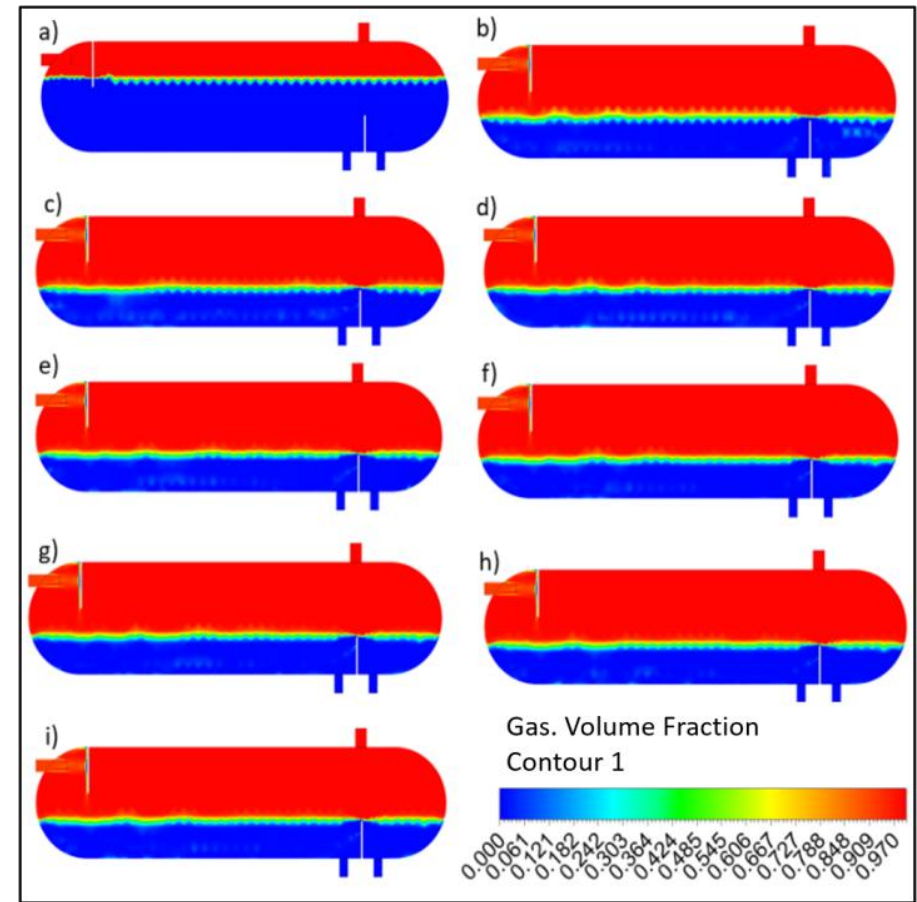

Figure 6. Natural gas volumetric fraction in a) 0 s, b) $150 \mathrm{~s}$, c) $300 \mathrm{~s}$, d) $450 \mathrm{~s}$, e) $600 \mathrm{~s}, \mathrm{f}) 750 \mathrm{~s}$, g) $900 \mathrm{~s}$, h) $1050 \mathrm{~s}$ and i) $1200 \mathrm{~s}$.

outlets stabilize at $0.25 \mathrm{~m} / \mathrm{s}$ - the value established by the modeling's boundary conditions. During the rest of the process, the liquid level remained, for the most part, constant, a little above the height of the overflow inlet diverter between the liquid separation sections. This allowed the oil to continuously overflow into the oil collection section, which allowed the equipment to operate properly.

ii. Although the separation of the components was relatively quick, the equipment took considerable time to reach a steady state 
condition. Only after approximately 470 seconds it was possible to obtain more oil than water at the oil outlet, and with 520 seconds the oil fraction came closer to the intended goal, reaching about $90 \%$.

iii. Even after the separation process had stabilized and the vessel had begun operating continuously, it was possible to notice a small accumulation of water at the bottom of the oil storage section, as shown in Figure 7.

iv. Following equipment stabilization, the separation of the phases does not happen completely. It is possible to observe both traces of oil in the water accumulation section (Figure 8) and the presence of gas dispersed in liquid phase (Figure 9). In the first case, because of the low flow velocity at the water outlet and the long period for which the mixture is retained, it is not possible to notice traces of oil in the outlet most of the time. In the second case, it was not possible to avoid completely the gas drag through the liquid phases. Fortunately, this dragging does not happen in an amount capable of

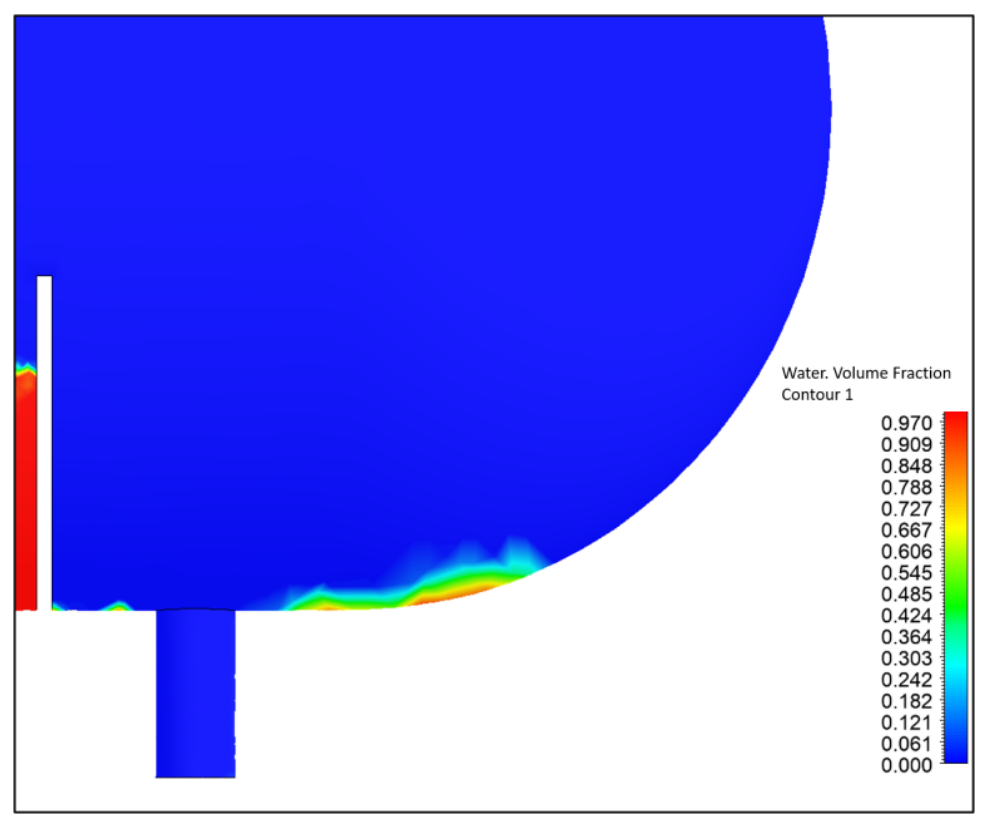

Figure 7. Detail of water accumulation in the oil accumulation section (1200 s).

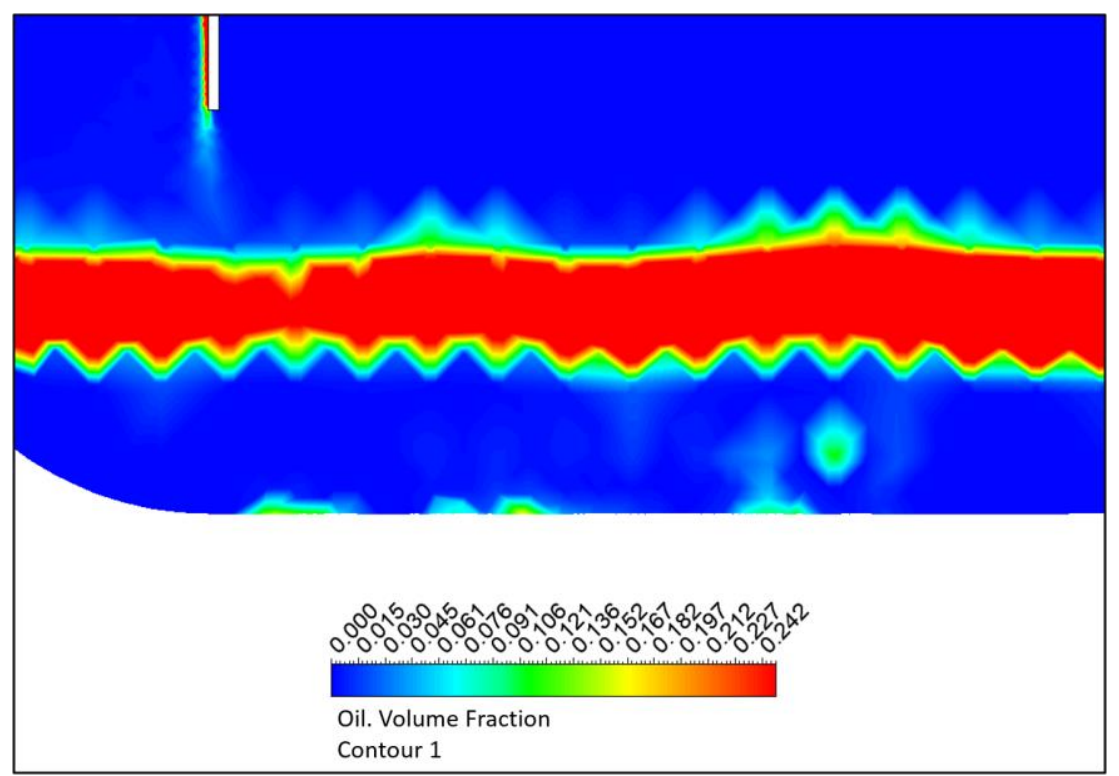

Figure 8. Traces of oil in the water accumulation section (1090 s). 


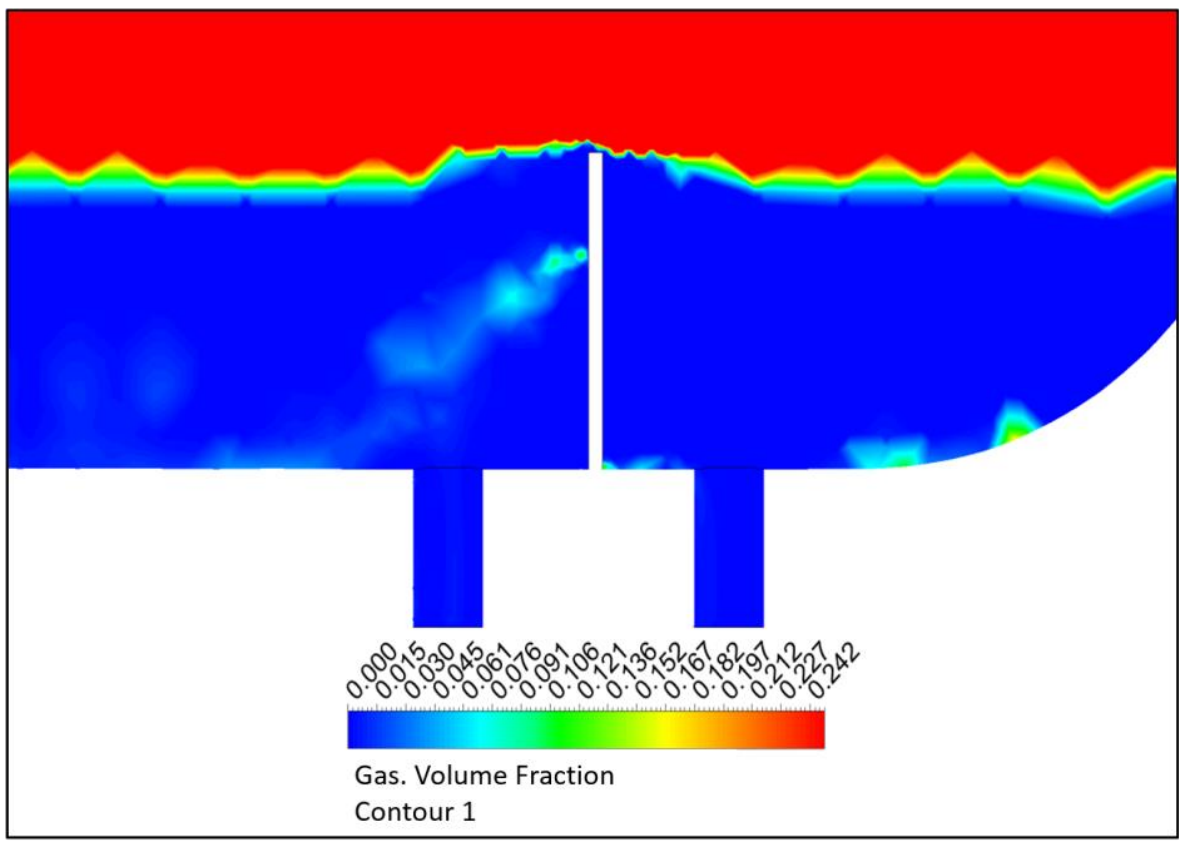

Figure 9. Gas traces in liquid accumulation sections (660 s).

compromising the process, with an average gas fraction of only $0.0322 \%$ at the water outlet and $0.2046 \%$ at the oil outlet.

\subsection{Variation of the physicochemical properties of oil}

Simulations were performed to evaluate the influence of the physicochemical properties of oil, obtaining the values shown on Table 2 . The results were, then, compared to the standard case. Figures $10,11,12$, and 13 show the oil fraction inside the separator to all the three cases for $300 \mathrm{~s}$ (5 minutes), $600 \mathrm{~s}$ (10 minutes), $900 \mathrm{~s}$ (15 minutes), and $1200 \mathrm{~s}$ (20 minutes), respectively.

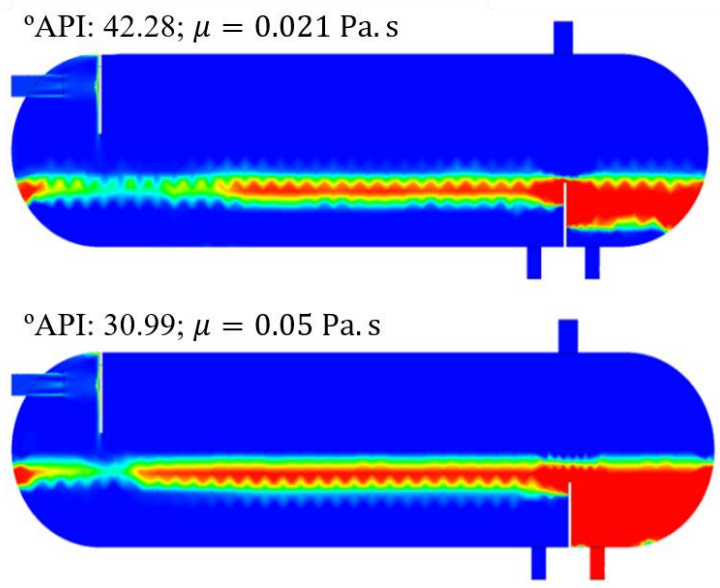

Observing Figures 10 to 13 , it is possible to see that the heavier and more viscous is the oil, the faster it fills the oil accumulation section the higher the liquid level is. For $30.99{ }^{\circ} \mathrm{API}$ oil viscosity, one can observe that the water overflows to the oil section. We can also notice the presence of traces of oil at the bottom of the water accumulation section.

Figure 14 shows a graph of oil volumetric fraction at the oil outlet.

Looking at the graph closely, it is possible to notice that the lightest oil case took more time to stabilize than the others. This occurred because it separates faster from the water, floating on it. So,

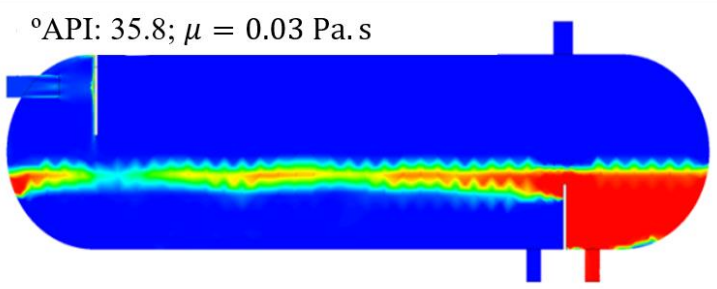

Oil. Volume Fraction

Contour 1

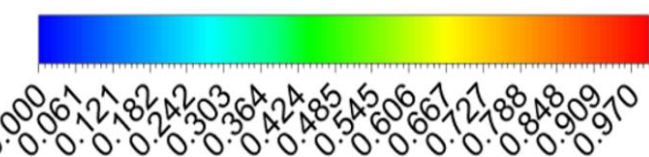

Figure 10. Oil volumetric fraction inside the separator (300 s). 

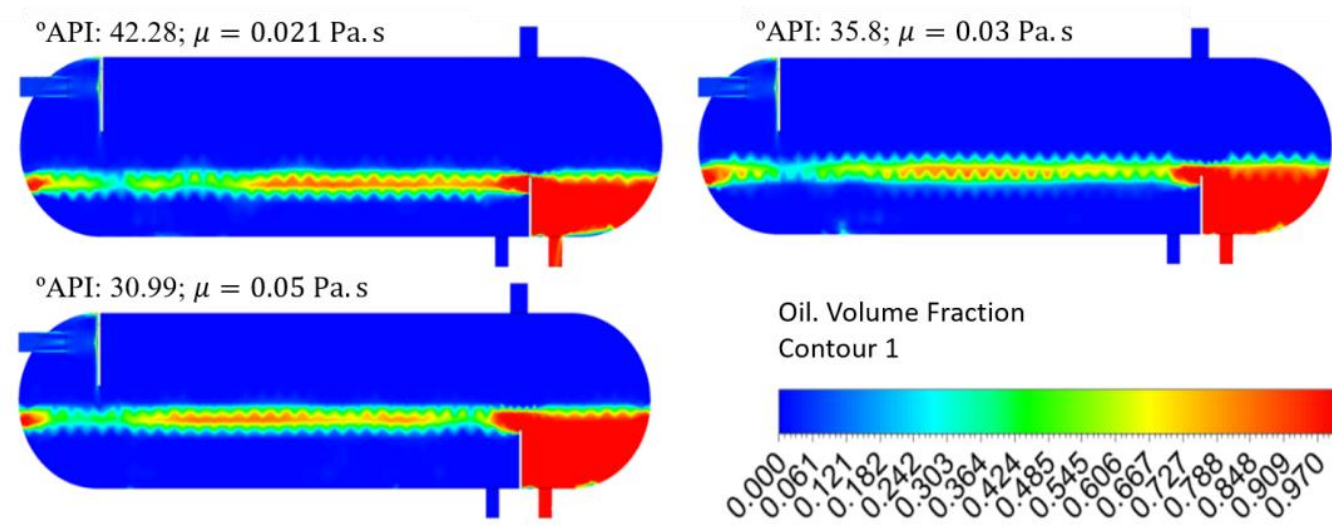

Oil. Volume Fraction

Contour 1

Figure 11. Oil volumetric fraction inside the separator (600 s).
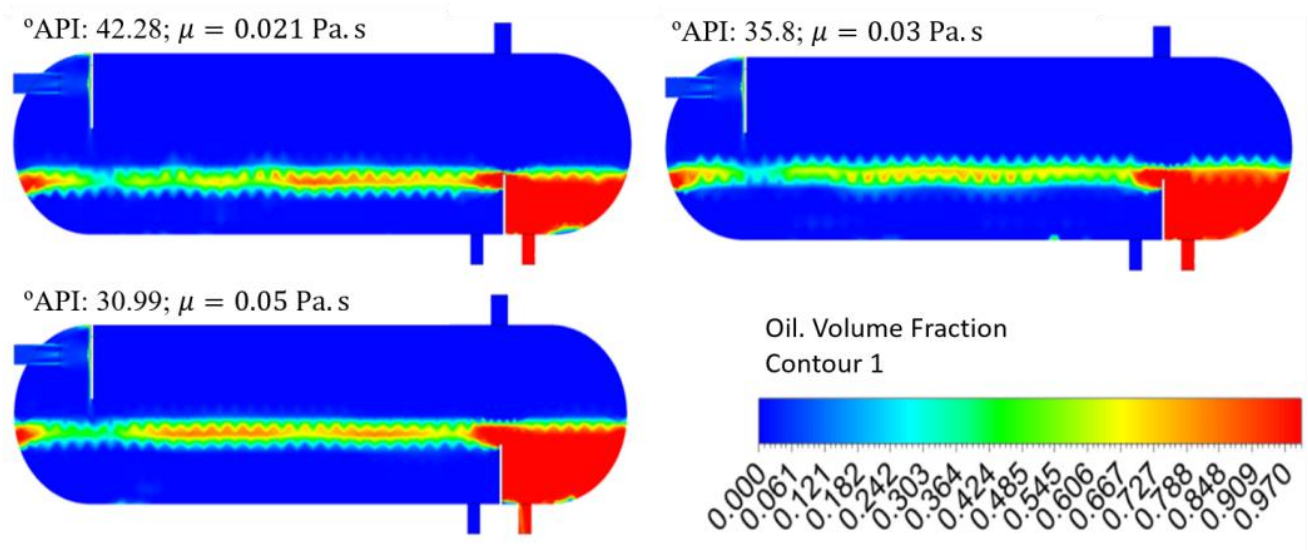

Oil. Volume Fraction Contour 1

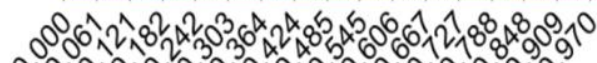
0.0 .0 .0 .0 .0 .0 .0 .0 .0 .0 .0 .0 .0 .0 .0 .0$.

Figure 12. Oil volumetric fraction inside the separator (900 s).

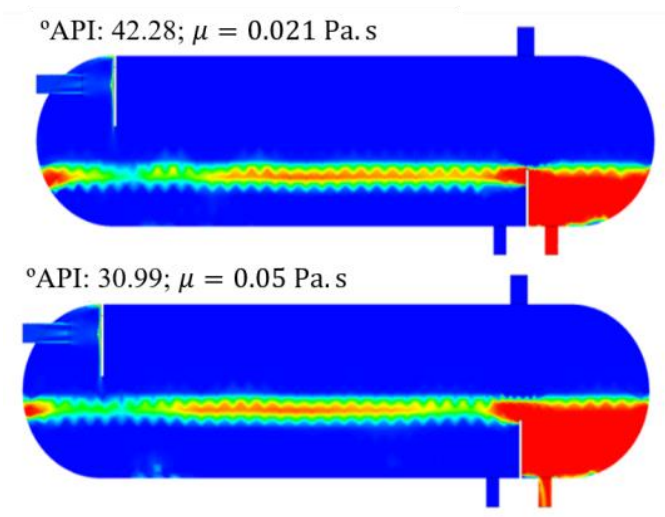

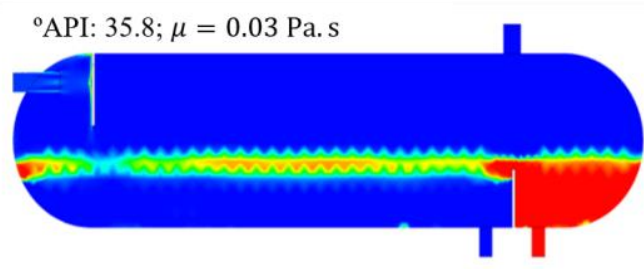

Oil. Volume Fraction Contour 1

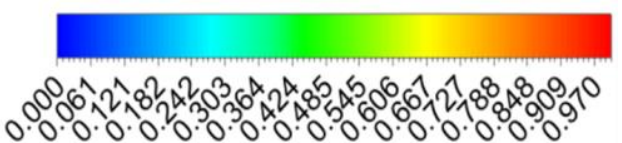

Figure 13. Oil volumetric fraction inside the separator (1200 s).

all the water in the oil accumulation section must flow to stabilize the process. However, this case could maintain a good separation for the rest of the simulation time, while in the case of the heaviest oil, there was a sharp loss of efficiency from 600s onwards, when the water from the water accumulation section overflows, flooding to the oil accumulation section.
The graph shows a strong oscillation between 130 and 170 seconds. This happened because during the stabilization process, the oil went down very quickly leaving a large accumulation of water, as can be seen on Figure 15. When the water is drained, the stabilization process continues.

Figure 16 shows the graph of the oil volumetric 


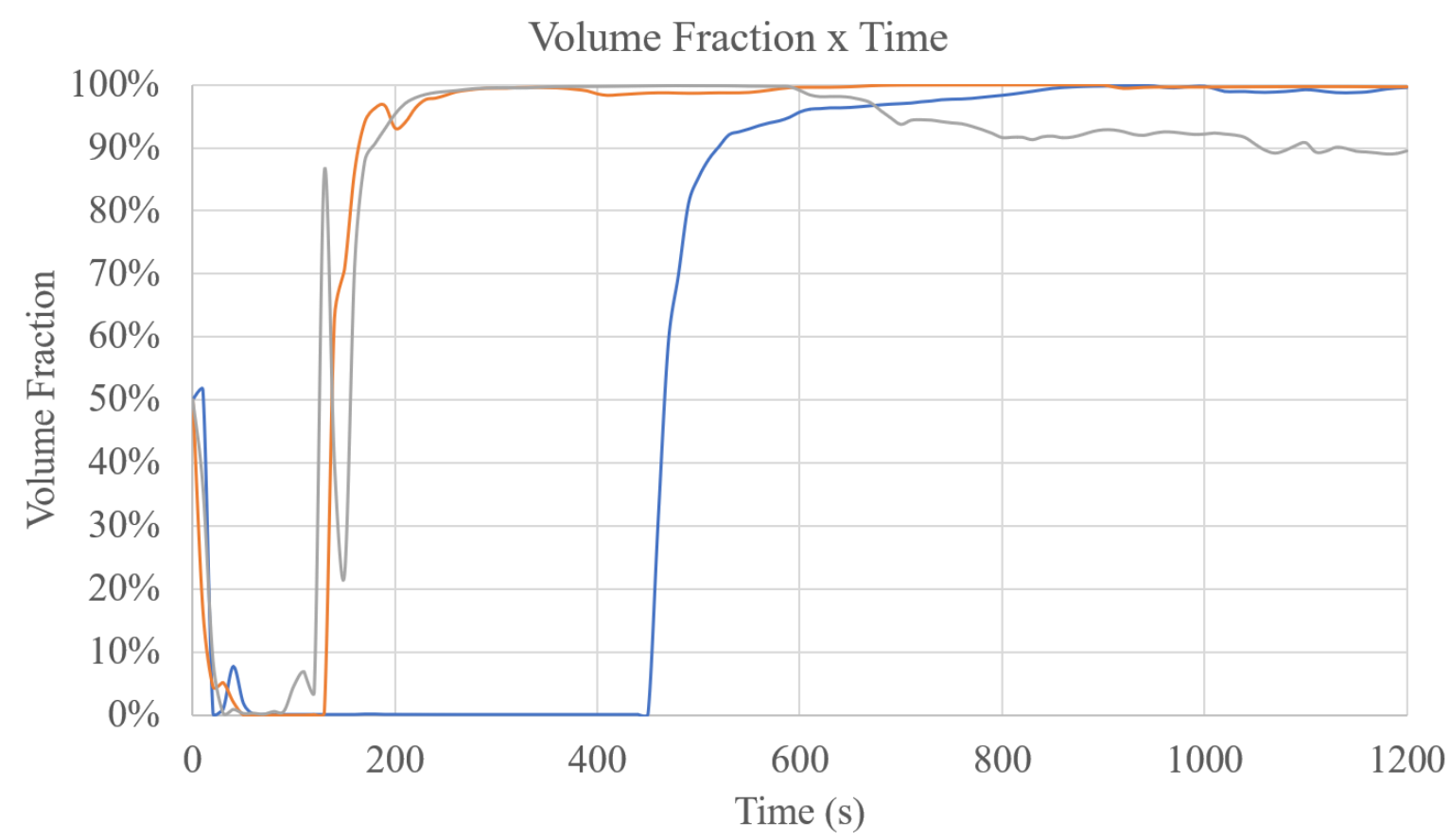

Figure 14. Graph of oil volumetric fraction in the oil outlet.

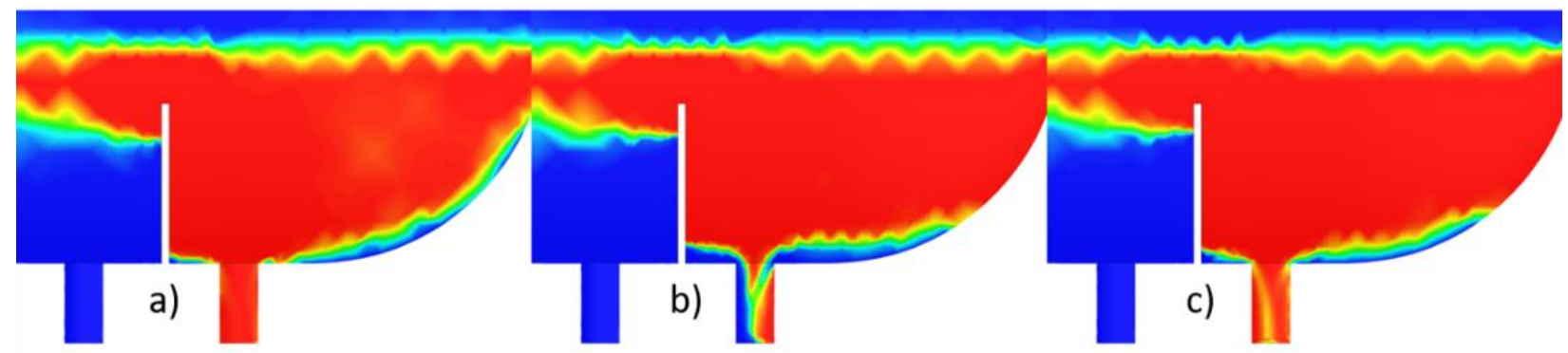

Figure 15. Oscillation observed on Figure 14 for a) $130 \mathrm{~s}$; b) $150 \mathrm{~s}$ and $170 \mathrm{~s}$.

fraction at the oil outlet for the last 10 minutes of simulation.

Except for the heaviest oil case, there was no significant difference in separation process efficiency. The $35.8{ }^{\circ} \mathrm{API}$ oil viscosity, although heavier and more viscous, still separates from the oil with relative ease, and the overflow problem seen in the $30.99{ }^{\circ} \mathrm{API}$ oil does not occur. At the end of the simulation, the oil volumetric fraction at the oil outlet was $99.6074 \%$ for the $40.28{ }^{\circ} \mathrm{API}$ oil, $99.6602 \%$ for the $35.8{ }^{\circ} \mathrm{API}$ oil, and $89.5031 \%$ for the $30.99{ }^{\circ} \mathrm{API}$ oil. The water and gas outlet presented similar results.

Figures 17, 18, and 19 show the streamlines for oil, water, and gas, respectively.
The heaviest oil case presented more turbulence through water and oil. The increase in oil viscosity increases the drag between fluids, causing a deceleration at the oil/water interface, resulting in circular movements. However, given the low overall velocity of the system after the shock of the inlet stream with the baffle, it is unlikely that these movements were responsible for the differences seen in the numerical results.

The most likely cause for the lower separation efficiency is the higher density and viscosity of the oil used. The increase in value of both properties considerably reduces sedimentation rate, making it harder to separate oil from water. A better configuration of the level controllers could help to avoid the problem seen with the heaviest oil, increasing the time the oil/water mixture is 


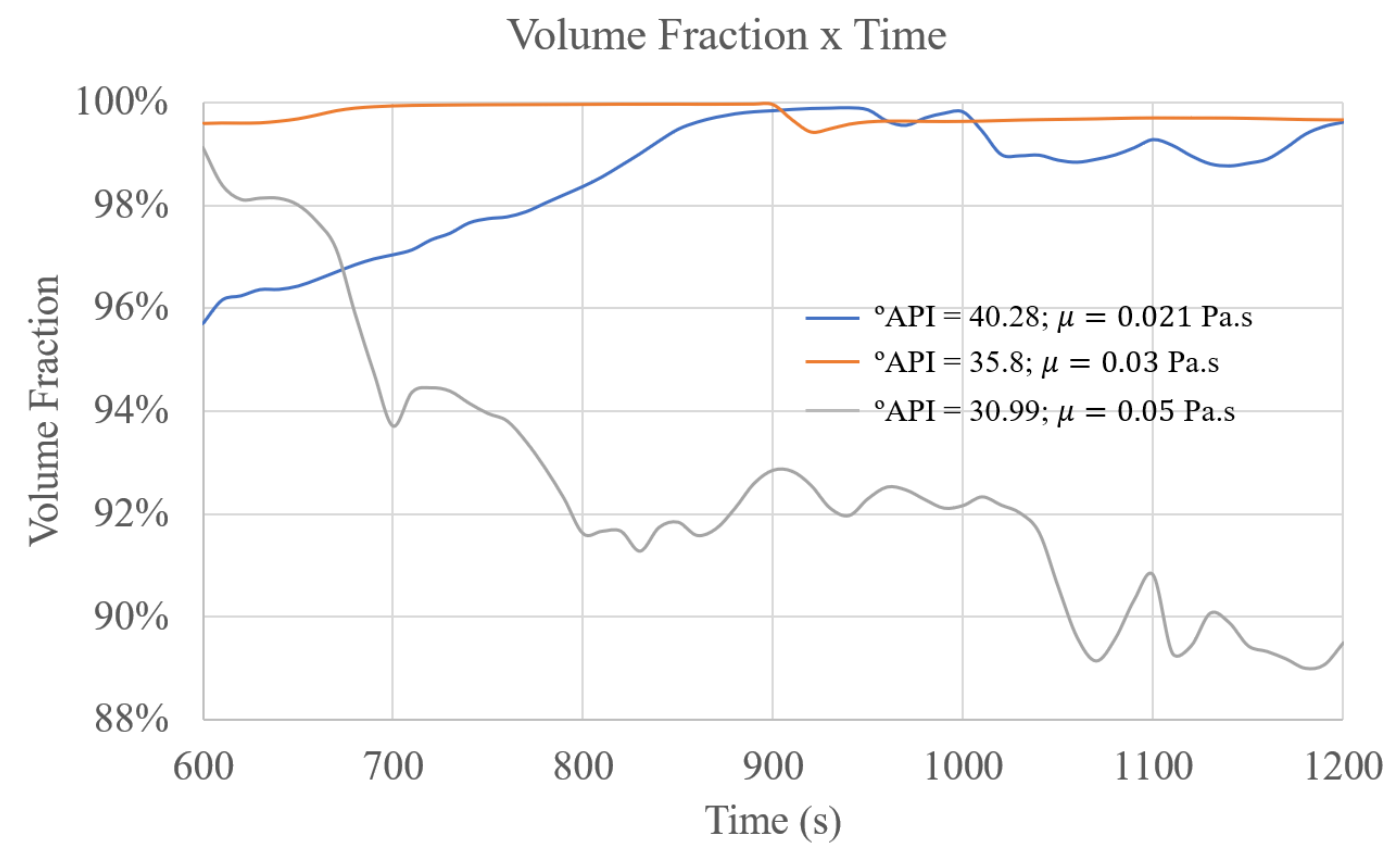

Figure 16. Oil volumetric fraction at the oil outlet for the last 10 minutes of simulation.
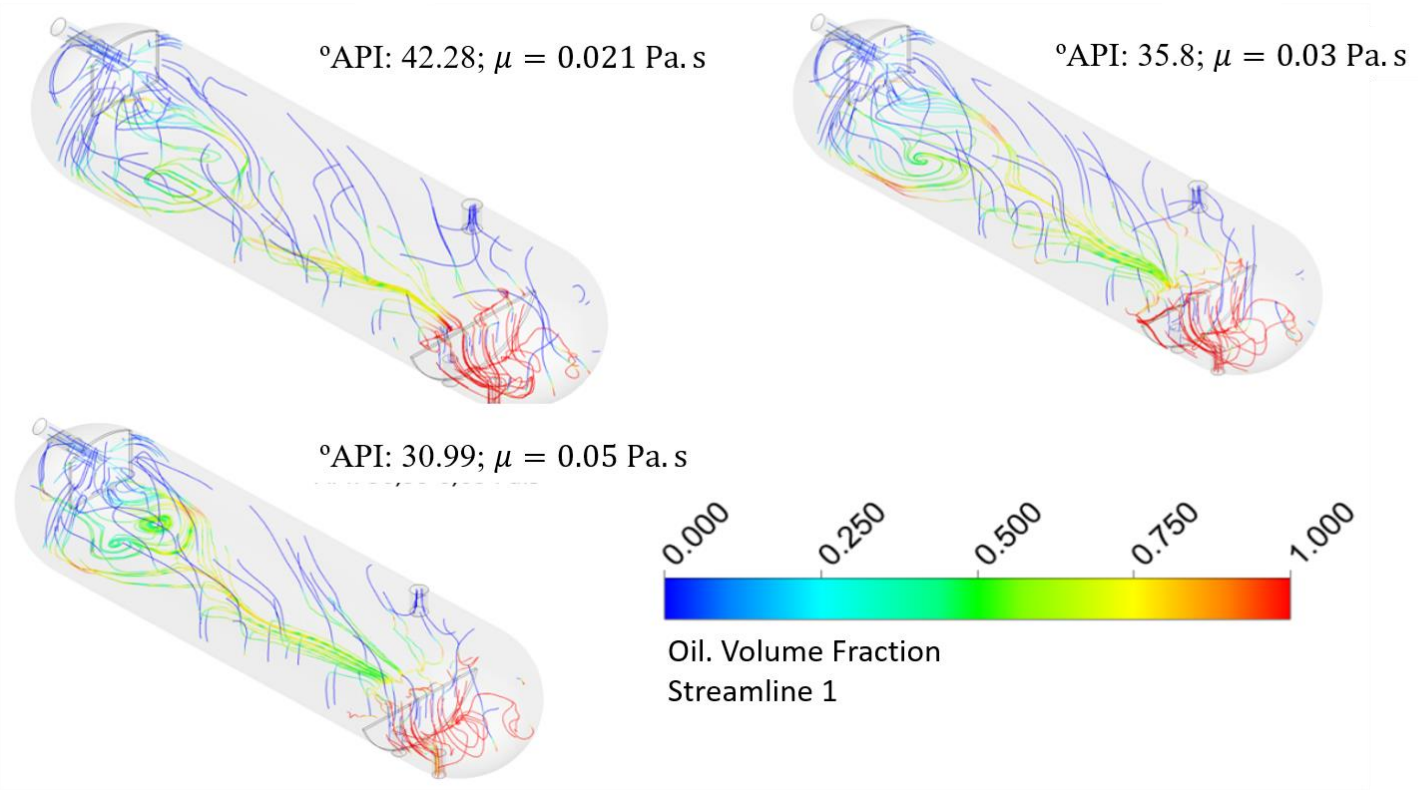

Figure 17. Oil streamlines (1200 s).

retained, which would prevent water overflow. In more extreme cases, such as the ones involving heavier and more viscous oils, a new dimensioning may be necessary.

\section{CONCLUSIONS}

Analyzing the results achieved through the simulations performed, it was observed that the mathematical modeling proposed to describe the fluid dynamics behavior inside a horizontal threephase separating vessel was able to reproduce satisfactorily the physical phenomena present in this type of equipment.

The study showed that the increase in oil viscosity and density may cause loss in efficiency of the vessel. After 20 minutes of simulation, for the 

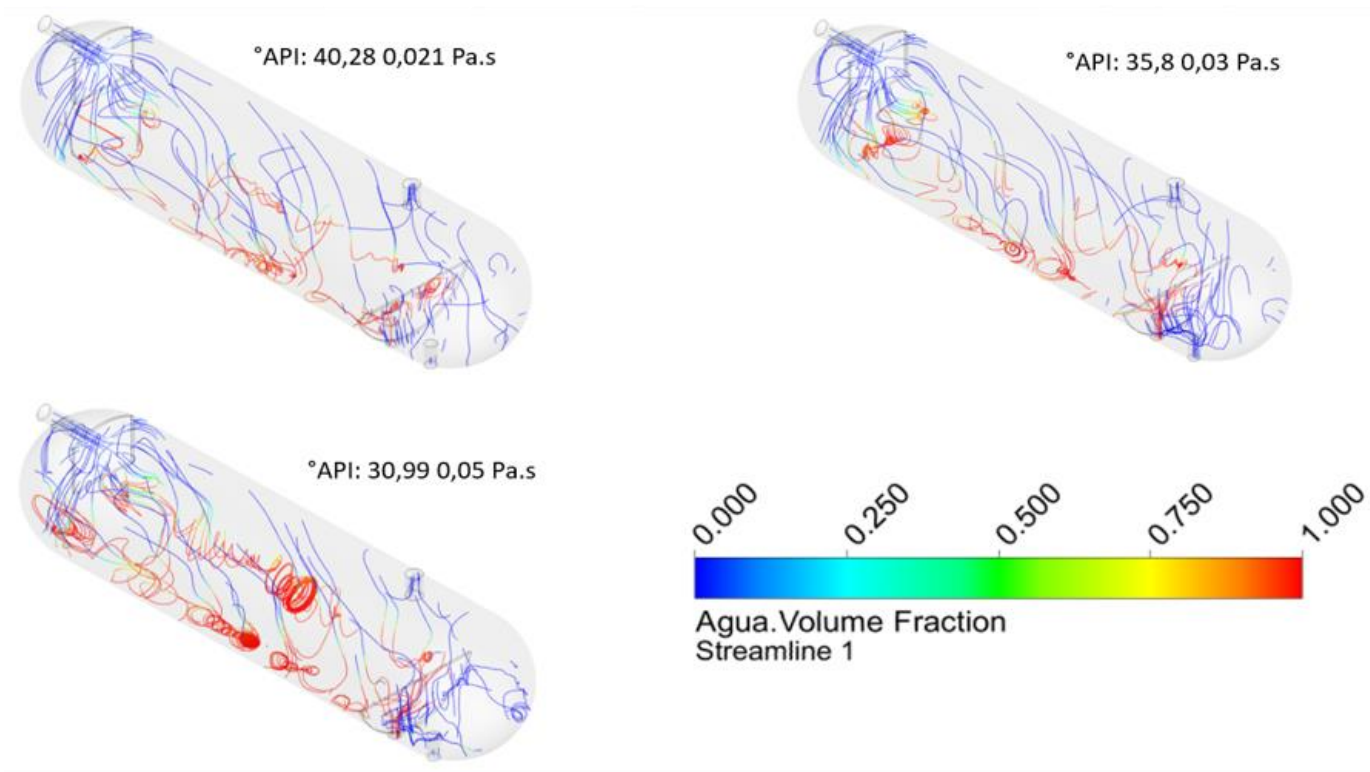

Agua. Volume Fraction

Streamline 1

Figure 18. Water streamlines (1200 s).
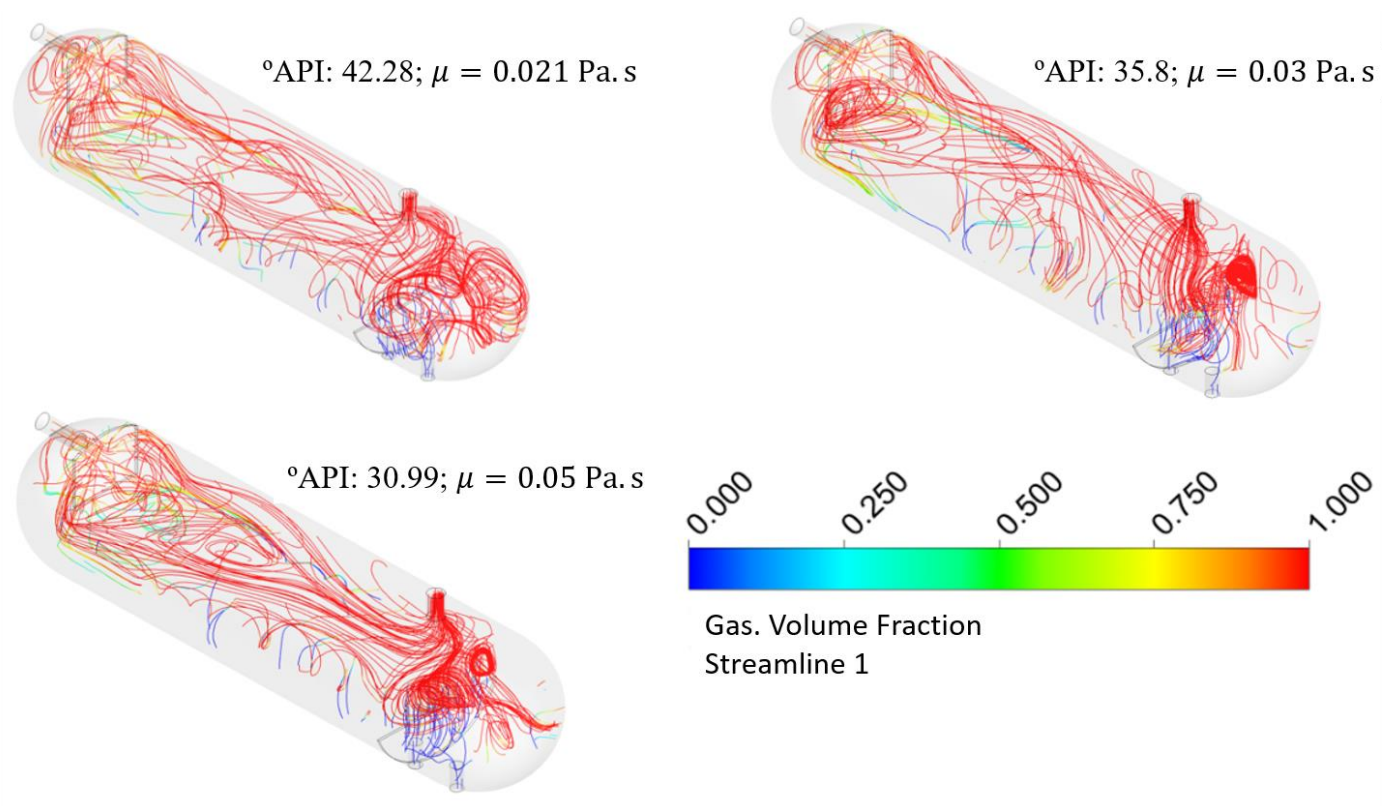

Gas. Volume Fraction Streamline 1

Figure 19. Gas streamlines (1200 s).

$40.28{ }^{\circ} \mathrm{API}$ oil viscosity, the volumetric fraction of oil at the oil outlet was $99.6074 \%$ against $99.6602 \%$ for the $35.8{ }^{\circ} \mathrm{API}$ oil and $89.5031 \%$ for the 30.99 ${ }^{\circ} \mathrm{API}$ oil. The increase in oil viscosity increases the drag between fluids, causing a deceleration at the oil/water interface, and reducing the sedimentation rate, hindering the separation. Adjustments in the separator vessel may be necessary to solve this type of problem. These adjustments may include a new configuration of the level controllers or even a new dimensioning of the entire equipment.

None of the cases studied presented problems related to liquid drag at the gas outlet, with values of approximately $100 \%$ of gas in practically all simulation time. There were also no problems in the water outlet, always presenting a minimum presence of unwanted fluids.

The computational fluid dynamics (CFD) proved to be a powerful tool in studying fluid behavior in several situations. Besides allowing a better 
understanding of the phase separation process, this type of software can be used to perform prior tests of various operating and sizing conditions, allowing a better prevention of operational problems in real situations, reducing risks of serious errors.

Future work in the field should investigate the influence of quality of the mesh on the results, perform simulations with even smaller time steps to obtain more precise results, test new sizing, and work on a more dynamic level controller system that better adapts to present conditions.

\section{NOMENCLATURE}

\section{Latin Letters}

\begin{tabular}{|c|c|c|}
\hline$r_{a}$ & volumetric fraction of phase a & - \\
\hline$\vec{U}_{\alpha}$ & speed of phase a & $\mathrm{m} / \mathrm{s}$ \\
\hline $\mathrm{T}$ & time & $\mathrm{s}$ \\
\hline $\mathrm{p}$ & pressure & $\mathrm{Pa}$ \\
\hline$A_{\alpha \beta}$ & $\begin{array}{l}\text { specific mass of the interfacial } \\
\text { area }\end{array}$ & $m^{-1}$ \\
\hline$\vec{U}_{\alpha}$ & speed of phase a & $\mathrm{m} / \mathrm{s}$ \\
\hline$\vec{U}_{\beta}$ & speed of phase $b$ & $\mathrm{~m} / \mathrm{s}$ \\
\hline$r_{b}$ & fraction of the dispersed phase & - \\
\hline $\mathrm{d}_{\mathrm{b}}$ & particle diameter of phase $b$ & - \\
\hline$k$ & turbulent kinetic energy & $\mathrm{kg} \cdot \mathrm{m}^{2} / \mathrm{s}^{2}$ \\
\hline$q_{s t}$ & $\begin{array}{l}\text { gas capacity at standard } \\
\text { conditions }\end{array}$ & MMscfd \\
\hline$D$ & vessel inside diameter & $\mathrm{ft}$ \\
\hline$p_{o p}$ & operating pressure & psia \\
\hline$T$ & temperature & ${ }^{\circ} \mathrm{F}$ \\
\hline$z$ & gas compressibility factor & - \\
\hline$K$ & empirical factor & - \\
\hline$q_{L}$ & liquid capacity & bbl/day \\
\hline$V_{L}$ & $\begin{array}{l}\text { sedimentation volume of the } \\
\text { liquid }\end{array}$ & bbl \\
\hline$t_{r}$ & retention time & $\min$ \\
\hline
\end{tabular}

\section{Greek Letters}

$\begin{array}{lll}\rho_{\text {巴 }} & \text { specific mass of phase } \alpha & \mathrm{kg} / \mathrm{m}^{3} \\ \tau_{\text {曰 }} & \text { tension of phase } \alpha & \mathrm{kg} / \mathrm{ms}^{2}\end{array}$

\begin{tabular}{|c|c|c|}
\hline$\tau_{\alpha}^{t u r b}$ & turbulent tension of & $\mathrm{kg} / \mathrm{ms}^{2}$ \\
\hline$\rho_{\alpha \beta}$ & $\begin{array}{l}\text { Reynolds in phase } \alpha \\
\text { mixing specific mass }\end{array}$ & $\mathrm{kg} / \mathrm{m}^{3}$ \\
\hline$\varepsilon$ & $\begin{array}{l}\text { rate of turbulent } \\
\text { dissipation }\end{array}$ & $\mathrm{m}^{2} / \mathrm{s}^{3}$ \\
\hline$\mu$ & dynamic viscosity & N.s $/ \mathrm{m}^{2}$ \\
\hline$\mu_{t}$ & turbulent viscosity & N.s $/ \mathrm{m}^{2}$ \\
\hline$\sigma_{k}, \sigma_{\varepsilon}$ and $C_{\varepsilon}$ & $\begin{array}{l}\text { dimensional constants of } \\
\text { the turbulence model k- } \\
\varepsilon \text {. }\end{array}$ & - \\
\hline$\rho_{L}$ & $\begin{array}{l}\text { specific mass of liquid } \\
\text { under operating } \\
\text { conditions }\end{array}$ & $\mathrm{lbm} / \mathrm{ft}^{3}$ \\
\hline$\rho_{g}$ & $\begin{array}{l}\text { specific mass of gas } \\
\text { under operating } \\
\text { conditions }\end{array}$ & $\mathrm{lbm} / \mathrm{ft}^{3}$ \\
\hline
\end{tabular}

Symbols

$\nabla \cdot \quad$ divergence operator

$\nabla \quad$ gradient operator

$\otimes \quad$ tensor product

\section{REFERENCES}

Ahmed, T; Russell, P. A.; Hamad, F.; Gooneratne, S. Experimental analysis and computational-fluid-dynamics modeling of pilotscale three-phase separators. SPE Production \& Operations., v. 34(4), 2019. https://doi.org/10.2118/197047-PA

Andrade, M. F. Dimensionamento de vasos separadores de petróleo. 42 f. Trabalho de Conclusão de Curso (Graduação em Engenharia de Petróleo) - Departamento de Engenharia de Petróleo, Universidade Federal do Rio Grande do Norte, 2014. (in Portuguese)

Anjos, R. C. N. S. Dimensionamento de vaso separador bifásico horizontal. $45 \mathrm{f}$. Trabalho de Conclusão de Curso (Graudação em Engenharia de Petróleo) - Departamento de Engenharia de Petróleo, Universidade Federal do Rio Grande do Norte, 2015. (in Portuguese)

ANSYS CFX Release 15.0. ANSYS CFX Introduction. SAS IP, Inc., 2013. 
COPERGÁS. Sobre o Gás Natural. Avaible in: http://www.copergas.com.br/index.php/produtos/ . Acessed on August $18^{\text {th }}, 2017$. (in Portuguese)

Diniz, N. J. B. Modelagem e simulação de um vaso separador bifásico horizontal: estudo de caso. $57 \mathrm{f}$. Trabalho de Conclusão de Curso (Graduação em Engenharia de Petróleo) Departamento de Engenharia de Petróleo, Universidade Federal de Alagoas, 2017. (in Portuguese)

EPE - EMPRESA DE PESQUISA ENERGÉTICA. Matriz Energética e Elétrica. 2018. Disponível em: $<$ \{http://www.epe.gov.br/pt/abcdenergia/matrizenergetica-e-eletrica\}>. Accessed on May $20^{\text {th }}$, 2020. (in Portuguese)

Ghaffarkhah, A.; Shahrabi, M. A.; Moraveji, M. K.; Eslami, H. Application of CFD for designing conventional three phase oilfield separator. Egyptian Journal of Petroleum, v. 26(2), p. 413420,2017 . https://doi.org/10.1016/i.ejpe.2016.06.003

Kharoua, N.; Khezzar, L.; Saadawi, H. N. H. Using CFD to model the performance of retrofit production separators in Abu Dhabi. Abu Dhabi International Exhibition \& Conference, SPE161521-MS, Abu Dhabi, 2012. https://doi.org/10.2118/161521-MS

Nakayama, Y. Introduction to Fluid Mechanics. $1^{\text {st }}$ ed. Oxford: Reed Educational and Professional Publishing Ltd, 1999. https://doi.org/10.1016/B978-008-102437-9.00001-2
Scapin, N.; Cadei, L.; Montini, M.; Montenegro, G.; Bianco, A.; Masi, S. An Eulerian-Eulerian approach for oil \& gas separator design. In: Offshore Mediterranean Conference and Exhibition, Ravenna, Italy, 2017 May 10.

Silva, A. L. F.; Souza Filho, J. E.; Ramalho, J. B. V. S.; Melo, M. V.; Leite, M. M.; Brasil, N. Í; Pereira Junior, O. A.; Oliveira, R. C. G; Alves, R. P.; Costa, R. F. D.; Kunert, R.; Gomes, W. Processamento primário de petróleo. Universidade Petrobras Escola de Ciências e Tecnologia E\&P [S.I: s.n.]. 2007. (in Portuguese)

Silva, R. P. Geração e caracterização reológica de emulsões de água em óleo pesado para aplicações em projetos de separadores gravitacionais. Tese (Mestrado em Ciências e Engenharia de Petróleo) - Instituto de Geociências, Universidade Estadual de Campinas, Campinas. 2004. (in Portuguese)

Silva, L. D. S., Marinho, J. L. G. Study on Pressure Drop and Liquid Volume Fraction of the Oil-Gas Flow in a Vertical Pipe Using CFX and the Beggs and Brill Correlation: Viscosity Effects. Brazilian Journal of Petroleum and Gas, Natal, v. 10, n. 1, p.1-8, 2016. https://doi.org/10.5419/bjpg2016-0001

Triwibowo, B.; Prasetiawan, H.; Hisyam, A.; Fauzan, M. F., Rizky, M. H. Modeling and simulation of steady state model approach for horizontal three phase separator (HTPS). In: AIP Conference Proceedings, AIP Publishing LLC, v. 1818(1), p. 020062/1 - 020062/6), 10 Mar 2017. https://doi.org/10.1063/1.4976926 